\title{
E-learning and Knowledge Management: Bridging Technological Gaps Can Bridge Knowledge Gaps in Ghanaian Universities
}

\author{
${ }^{1}$ Joy Okah, ${ }^{1}$ Victor Teye, ${ }^{2}$ Charles Shoniregun \\ ${ }^{1}$ Ghana Institute of Management and Public Administration \\ ${ }^{2}$ Infonomics Society, UK and Ireland
}

\begin{abstract}
E-learning has become a necessary tool in the developmental agenda of every progressive institution for an effective delivery of the knowledge management system. The specific objectives of this study is to explore whether 1) E-Learning has improved knowledge management in these institutions, and 2) technological barriers has constrained individuals to the improvement of knowledge management in their institutions.

This paper investigates the integration of $e$ Learning and Knowledge Management in the dimensions of knowledge generation, capturing, sharing and application in Ghana using five major public universities as case studies. It attempts to unveil the e-learning and knowledge management policies in place at these institutions, and to know the extent to which these policies are catching up with the intended beneficiaries. The situation analysis was carried out by interviews conducted with policy makers at the institutions, and survey among participants (students and lecturers) within the scope of technological and regulatory factors at the case study institutions.

Findings from the interviews suggest that $e$ learning has contributed to knowledge management in their respective institutions. Overall, this study contributes to the debate whether bridging technological gaps can bridge knowledge gap in Ghanaian institutions.
\end{abstract}

\section{Introduction}

This article explores e-learning and knowledge management in Ghanaian universities. Over the past few years there have been a renewed interest among practitioners and academicians as regards the knowledge gap between institutions in the developing and developed countries. A development arising from the move away from the traditional methods of face to face learning to the ubiquitous methods of learning which deals with extensive elearning mechanisms. E-learning is the online delivery of information for the purpose of education, training, knowledge management or performance management (Turban and King, [33]). Knowledge management is the capturing, creating, storing, protecting and updating of knowledge constantly and using it when necessary to improve the functioning of an organization (Turban et al [34]; Turban and King [33]).

The concept e-learning has been adopted as an innovative teaching mechanism, due to the evolution of the way business is now conducted globally (Okah [24]) and this has been a major concern for institutions of the developing countries (UNCTAD, [35]). Many universities in developing countries have been unable to meet up with the virtual education (Mohamedbhai [22]) commonly referred to as e-learning and this has created a perception that there is a knowledge gap within these institutions (Morroco [23]). Most studies in the area of knowledge management and e-learning has concentrated on the benefit of e-learning on higher education (Okah [25]; Insitful et al. [11]; Mohamedhai [22]). As such, compared with the notion of the technological gap between developed and developing countries (Periera \& Plonski [28]; UNCTAD [35]), extant studies have not explored the connection between knowledge gap and technological gap at universities in developing countries. This is an important gap in literature given that there is a perception of knowledge gap at institutions of developing countries (Evers [6]).

Although evidence of the knowledge gap in developing countries' universities is mixed according to a World Bank [38] report which distinguish two types of knowledge as the following firstly, the knowledge about attributes leading to information problems which is referred in this article as knowledge gap. The second kind of knowledge is the knowledge about technology and the concept of a gap is referred for the purpose of this research as a technological gap. The enactment of e-learning seems to be growing particularly with Nigeria and Ghana in Africa (UNCTAD [35]).

Although the e-learning notion has improved knowledge management, some scholars argue that its impact is exaggerated. The theoretical base of elearning bridging the knowledge gap has been criticized by some scholars (Evers [6]; Elearningpost [5]) suggesting that even with the "the know how" of technology it is uncertain if the knowledge gap will be bridged as there is still the disparities of rich and poor between developed and developing countries. This article addresses some of these concerns.

The article progresses in this dimension and the next section draws on broader literature simulation of barriers of knowledge management and technologies 
of e-learning. Moreover, it widens existing empirical scope by going beyond the Western concept (a gap this article sets to address) in which the existing studies are framed (Okah [25]; Jonassen et al [13]; Mayer [21]) to explore e-learning and knowledge management in Ghanaian universities and to project how the knowledge gap can be bridged.

\section{Review of Relevant Literature}

\subsection{Barriers to Knowledge Management}

One research perspective that needs greater attention is the barrier to knowledge management. The barrier to knowledge management would be discussed in the phases of knowledge generation, capturing, sharing and application. Potential factors that could constitute barriers within these phases would be discussed below.

2.1.1. Knowledge Generation. This is the creation of knowledge for a specific problem or area. The barrier towards knowledge management from elearning is overestimating what e-learning can accomplish (Turban et al [34]). It is argued that people sometimes do not understand the limitations of e-learning they therefore expect too much.

2.1.2. Knowledge Capturing. This is gathering new knowledge and storing it in a machine readable form. The barrier to knowledge capturing is that the right technological tools might not be used or there might be too much fixation on technology as a solution (Neal [26]).

2.1.3. Knowledge Sharing. This is making knowledge available in a useful format to anyone in an organization who needs it. The barrier to knowledge sharing is that not everyone uses elearning due to internet availability and knowledge so knowledge sharing is limited to the niche of the market that utilizes e-learning, thus "learning to love and work with computers must figure amongst the more obvious 'attainment targets' of any contemporary educational curriculum” (Littleton \& Light, [20]).

2.1.4 Knowledge Management Application. Like a library, knowledge must be kept current. It must be reviewed to verify it is relevant and must be kept accurate. According to Turban and King [33], the setbacks as regards knowledge management application is the cost and time of keeping e-learning materials up to date.

\subsection{E-learning Technologies}

The literature about technology acquisition is extensive and empirically oriented (Westphal et al.,
[37]; Lall, [18], [19]; Kim, [14], [16]; Kim and Nelson, [17]). Therefore, the definition of e-learning technologies is dependent on the researcher's interpretation. For example, as stated by Lall [18], technology acquisition is related to the operations management of the firms or the day-to-day creation and delivery of products and services and the technical characteristics that pertain primarily to the engineering principles involved in creativity.

In educational settings, e-learning technologies and the Internet have opened new pathways of learning. A review of studies related to electronic technology and student achievement by SivinKachala \& Bialo [31] reported positive and significant gains for students who were engaged in technology-rich environments. Those students showed significant gains and achievement in all subjects, increased achievement and improved attitude toward their own learning, and increased self-esteem. According to Hutinger [10], computers provide diverse tools for students with disabilities that encourage autonomous behavior as well as increase the probability that they will interact with their learning environment. Further, technology-rich classrooms utilize multimedia to increase student interactions and enhance student learning. Students can benefit by e-learning when technology is used for complex problem solving and informationretrieving purposes (Jonassen et al., [13]). Harris [8] observed that technology will be a significant tool to recreate learning in the 21st Century. However, educators will need to experience a paradigm shift in their vision for technology in higher education. Further, they need to change their beliefs in learning processes.

\subsection{The Institutional Approach}

A major stream of research from which this article draws is institutional theory. This theory is related to the concept of adaptation, conformity and convergence to institutional environments. The institutional approach has been adopted by different disciplines and the existing literature on institutional theory is too extensive to be adequately summarized here (see Hodgon [9], for a more comprehensive review).

A particular useful framework for understanding e-learning and knowledge management within the institutional approach is which explains the integration of e-learning as understanding and negotiating the relationships between these three components of knowledge- pedagogical content knowledge, technological content knowledge and pedagogical technological knowledge.

2.3.1. The Institutional Theory and the Ghanaian Universities' context. As a country with relatively easy access to education, Ghana has a 
population of 23.4 million in 2008 (World Bank Report [38]). Although e-learning could offer a variety of benefits to the educational sector, unfortunately most universities in Ghana are slow to adopt the e-learning and knowledge management strategies. In order to facilitate this slow move, the government established the Ghana Investment Fund for Electronic Communications (GIFEC) to promote research and reading culture, by providing access to information and help increase direct participation in development and decision making processes (Bokpe [2]). Despite these massive investments in ICT infrastructure and ICT-capacity building, Ghana is still to a large extent digitally isolated from the Global Village because it lacks the critical drive and strategies to harness the full potential of ICT for the socio-economic development of the country (Insitful et al. [11]). Within the Ghanaian Universities context, bridging the technology gap is an on-going process as the Ministry for communication, embarked on a project to extend fiber optic facility to all parts of the country to enhance e- learning (Business news report [3]).

2.3.2. Case Studies. A case study has multiple meanings that can be used to describe a unit of analysis (e.g. a case study of particular business), or to describe a method (Shoniregun [30]). Saunders et al. [29] defined a case study as a research strategy that involves the empirical investigation of a particular contemporary phenomenon within its real life context using a multiple of evidence (p. 473). Jankowicz [12] describes a case study as a method used when you want to focus on a set of issues within a single organization, or focus on a smaller unit of analysis. The case studies include the five main universities in Ghana [35] using Webometics ranking and 4 International Colleges and University 2010 ranking based on size, visibility and relevance to academic publication activities. The major institutions include University of Ghana, Legon Accra (UG), the Kwame Kruma University of Science and Technology (KKUST), Ashesi University College (AUC), Ghana Institute of Management and Public Administration (GIMPA) and the University of Cape Coast (UCC).

\section{Research Approach}

This study is rooted in the phenomenological research approach which emphasizes individual's live experience and adopted more of a qualitative method involving semi-structured interviews.

\subsection{The Interview}

A total of 25 semi structured interviews were conducted involving 16 males and 9 females. The participant's involvement with the institution is one year and above. Participants were drawn from researcher's existing network through a snowballing approach. Saunders et al. [29] suggested that in order to request access, existing contacts should be used to develop new ones. Their knowledge of us means they would be able to trust our stated intentions and also help credibility with new contacts. This involved asking participants to recommend other people within or outside their organization (Okah [24]). The snowballing approach is considered acceptable for exploratory studies (Green et al [7]).

Each interview commenced with the purpose and objective of the research as well as establishing the issues of confidentiality. The interviews were conducted in person at several locations depending on the subject's choice of venue and also through telephone based on eligible participant's preference. The interviews lasted between fifteen to thirty minutes depending on how fast the respondents were in answering the questions. The participants were asked about their experience on knowledge management and e-learning.

The questions were intentionally open-ended with prompts used to expand discussion when necessary and to further elicit the views and clarify opinions of participants (Cresswell [4]).

\subsection{Data Analysis and Research Findings}

To facilitate the job of the researcher, all the 25 interviews were tape recorded and transcribed with the help of a research assistant. Data Analysis followed a closely grounded theory approach (Strauss \& Corbin [32]). Firstly, by open coding based on situation analysis the breakdown was done by reading the transcript carefully and indexing each case. Secondly, by axial coding which involves development of categories (including Institution, gender and Job). Thirdly, by investigating interconnectivity, for instance those that have similar constituents of e-learning were grouped together during the data analysis. To enhance the validity of this processes, independent coding by a random sample of the transcript were undertaken by researchers, both familiar with research objectives. Data was analyzed separately and corroboration given to statements based on the importance of responses to research questions based on pattern checks.

The respondents and responses to each question were coded consecutively in a Male (M) or Female (F) and Yes (Y) or No (N) format depending if the respondents answers the questions. The respondents comprise of $36 \%$ female and $64 \%$ male which is illustrated diagrammatically (see Figure 1). 
Table 1. Coded Research Responses based on Situation Analysis

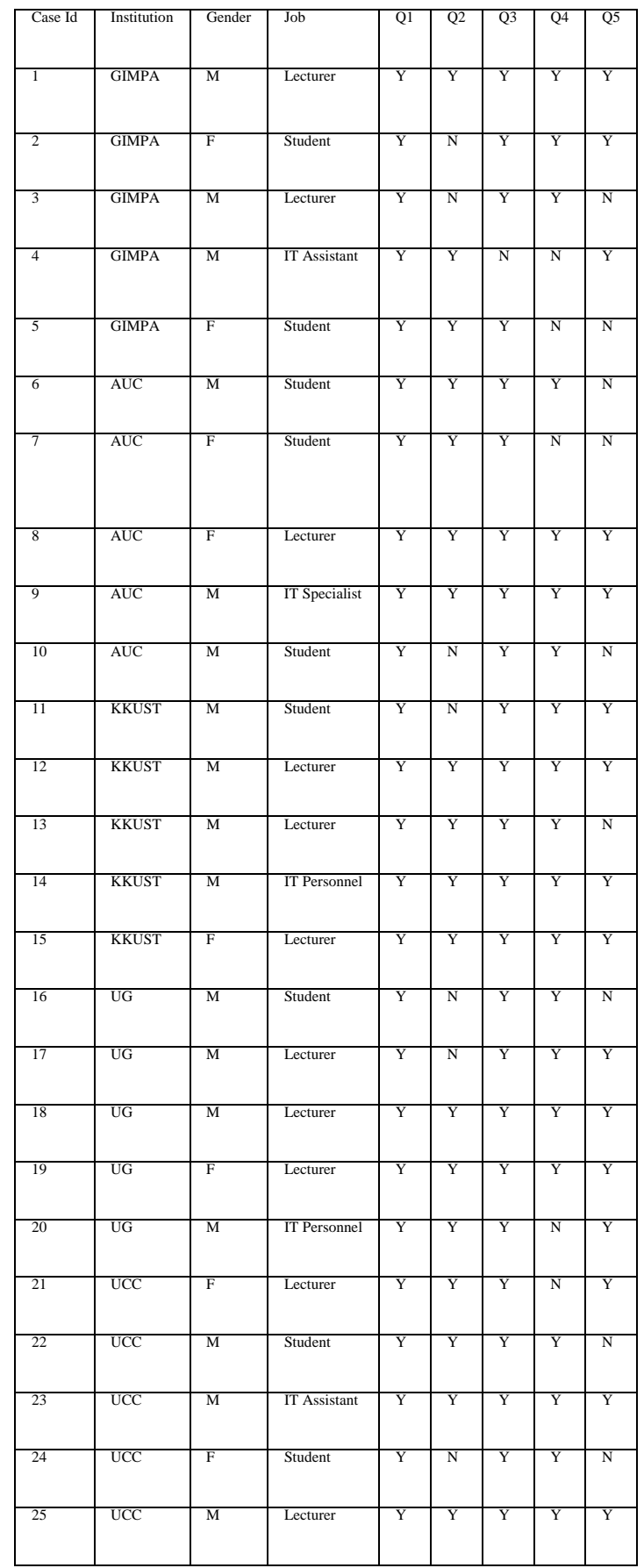

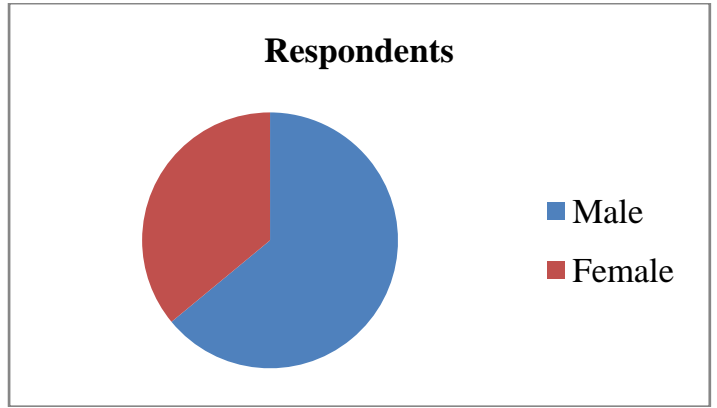

Figure 1. Coded Research Responses

Data was classified based on the responses of each participant. Question 1 had a 100\% response rate; question 2 had a $72 \%$ response rate, question 3 had a $96 \%$ response rate, question 4 had a $75 \%$ response rate and question 5 had a $60 \%$ response rate and this is graphically represented in Figure 2.

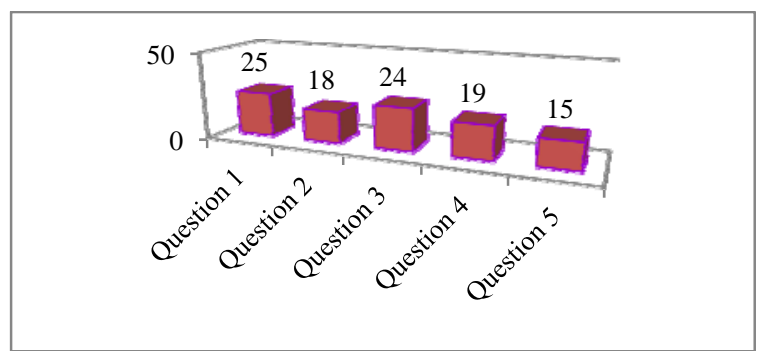

Figure 2. Coded Research Responses

The findings of this study indicated that people's perception of e-learning differs which agrees with Lall's [18] statement (see section 3). $75 \%$ of respondents identified the constitute of e-learning as computers and internet connectivity which align with Turban and King's 2003 definition and 25\% of respondents identified the constituents of e-learning as going beyond the internet of inclusion of other classroom technologies which corresponds with Hutinger's definition of e-learning [10]. The statements below illustrate that effect.

"What constitutes e-learning is the internet and P.C's connection”. (Male, Student University of Ghana).

"Using the internet to obtain information or to send information is part of the process, also with the use of projectors in the classroom”. (Male, Lecturer, Ghana Institute of Public Administration).

There is also an indication that there were certain factors that constitutes barriers to e-learning technologies with Ghanaian Institutions which ranges from adequate switches, access to some online materials, low bandwidth e.t.c; which corresponds more to the knowledge sharing barriers. 
There were no consistent response pattern of differences based on the job role and overall, the results suggested that learning has improved knowledge management at their institutions.

\section{Discussion}

This study is set out to explore the technological barriers that could bridge the knowledge gap and how knowledge can be improved in Ghanaian Universities. The findings provide evidence for the continued significance that bridging the technological gap can bridge the knowledge gap at Ghanaian universities. The findings further provide evidence that the knowledge gap cannot be bridge with just an availability of the technology but a further need to use them therefore an implication for management and policy makers is to ensure that the technology is not just been provide but used by providing necessary trainings and enforcing the usage to bridge the knowledge management gap.

This research represents few empirical studies that have explored the technological gap relationship with the knowledge gap and contributions notwithstanding, this study has some limitations which also provide promising new direction for future research. Due to the institutional approach, there is a perception that the inclusion of the participation of more universities could enhance data collected using a longitudinal approach. Although the interviews were administered to five major universities in Ghana, but there is a scope for creating a directory of accredited universities in Ghana and extending the participation to more universities. Secondly, the scope can also be extended to participation of other universities of other developing countries to get a broader view in exploring this phenomenon over time. Thirdly further studies could replicate this study in different national context. Fourthly, further extension of this study could examine the correlation of responses among the participant with respects to their job roles.

\section{Conclusion}

The aim of this study was to examine whether bridging the technological gaps can bridge the knowledge gap in Ghanaian Universities, a neglected context in the knowledge management and elearning literature. The study contributes the larger debate of technology bridging the knowledge gap with institutions in a non Western context (Ghana). Although there are some evidence of technology bridging the knowledge gap but the author argues that the availability of the technology does not bridge the gap but using them efficiently would bridge the gap. It points to the need of advancing beyond availability of technology to ensuring the usage to yield the benefits and bridge the knowledge gap.

\section{Acknowledgements}

We want to thank Professor Franklyn Manu (Business School, Ghana Institute of Management and Public Administration), Dr Afam Ituma (Brunel Business School), for their contributions to this paper.

\section{References}

[1] 4 International Colleges and Universities (2010) Universities in Ghana by 2010 Ranking. Available at http://www.4icu.org/gh/, (Accessed $11^{\text {th }}$ October 2010).

[2] Bokpe S. (2010) "National School ICT Connectivity Project Inaugurated” Daily Graphic Nov 22 2010. Available

http://www.modernghana.com/news/305241/1/nationalschool-ict-connectivity-project-inaugurat.html (Accessed 22nd Nov 2010).

[3] Business New Report (2007) "Fibre Optic to All part of the Country", Available at http://www.ghanaweb.com/GhanaHomePage/features/artik el.php?ID=119873, (Accessed $3^{\text {rd }}$ November 2010).

[4] Cresswell J. (2003) "Research Design: Qualitative Quantitative and Mixed Method Approaches". Thousand Oaks C.A SAGE,.

[5] E-learningpost (2010) "Computers at Home: Educational Hope versus Teenage Reality”. New York Times Report. Monday July 12, 2010. http://www.elearningpost.com/blog/computers_at_home_e ducational_hope_vs._teenage_reality, (Access date 6th August 2010).

[6] Evers, H-D. (2002) "Knowledge, Society and the Knowledge Gap”, a paper presented at the International conference of globalization, culture and inequalities. August 2002. University Keebasan Malaysia.

[7] Green P., Tull D., \& Albbuam S. (1995) "Gerald Research for Marketing Decisions” In Ituma \& Simpson (2009): Human Relations: The boundaryless career and career boundaries: Applying an institutionalist perspective to ICT workers in the context of Nigeria.

[8] Harris, P. (2000). "Using technology to create a new paradigm for a learner entered educational experience". Technos Quarterly, 9(2).

[9] Hodgson, G. (1994) "The return of Institutional Economies” In N. Smelsa \& R. Sedberg (Eds), handbook of economics sociology. Princeton, N.J: Princeton University Press and Russell Sage Foundation.

[10] Hutinger, P. (1996). "Computer applications in programs for young children with disabilities: Recurring themes". Focus on Autism and Other Developmental Disabilities, 13(1), 105-114, 124.

[11] Insitful, J., Okyere P., \& Osae S. (2003) "Use of ICT for Education, Research and Development in Ghana: 
Challenges, Opportunities and Potentials”. 2003 Round Table on Developing Countries Access to Scientific Knowledge, The Abdus Salam ICTP, Trieste, Italy.

[12] Jankowicz A. (2000) Business Research Projects, $3^{\text {rd }}$ Edition, Business Press Thomson Learning. Luton Business School, U.K.

[13] Jonassen, D., Howland, J., Moore, J., \& Marra, R., (2003). "Learning to solve problems with technology: A constructivist perspective" (2nd ed.)Upper Saddle River, NJ: Prentice-Hall.

[14] Kim, L., (1980) Stages of development of industrial technology in a developing country: a model. Research Policy, vol.9, n.3, p.254-277.

[15] Kim, L., (1997) "Imitation to innovation": the dynamics of Korea's technological learning. Harvard Business School Press, Boston.

[16] Kim, L., (1999) "Building technological capability for industrialization": analytical frameworks and Korea's experience. Industrial and Corporate Change, vol.8, n.l, p.111-136.

[17] Kim, L., Nelson, R.R. (Eds.), (2000) “Technology, learning, and innovation": experiences of newly industrializing economies. Cambridge University Press, Cambridge.

[18] Lall, S., (1990) "Building industrial competitiveness in developing countries”. OECD, Paris.

[19] Lall, S., (1993) 2Promoting technology development: the role of technology transfer and indigenous effort”. Third World Quarterly vol. 14. n.l, p. 95-108.

[20] Littleton, K., \& Light, P. (Eds.). (1999) "Learning with computers”: Analyzing productive interaction. New York: Routledge.

[21] Mayer, R.E. (2001). “Multimedia learning”. Cambridge, UK: Cambridge University Press.

Maykut P., and Morehouse, R. (1994) "Beginning Quantitative Research": A philosophic and pratical guide. London: Falmer Press.

[22] Mohamedbhai G. (2002) "Globalisation and its implications on Universities in Developing Countries". Globalisation: What issues are at stake for universities? University Laval, Quebec Canada.

[23] Morroco R., (2006) "Panel on bridging the technology gap within and within nations". Report of Commission of Science and Technology for Development, $9^{\text {th }}$ Session. UNTCAD secretariat.

[24] Okah J. (2010) "e-Procurement within the Oil and Gas Industry", A PhD thesis submitted to the University of East London. United Kingdom.

[25] Okah, J. '(2009) “Fostering Electronic Learning in Higher Education" published in the 7th Hawaii International Conference on Education, January 2009, Honolulu.
[26] Neal, L (2008) “Predictions for 2008” e Learn Magazine, January $12^{\text {th }}$ 2008. Accessed at http://www.elearnmag.org/subpage.cfm?section=articles\& article=58-1 (Access date 10 ${ }^{\text {th }}$ October 2010).

[27] Persuad A. (2001) “The Knowledge Gap”.

[28] Periera L. and Plonski G. (2010) Bridging the Technology Gap in Brazil: The Case of Photonics

[29] Saunders M., Lewis P. and Adrian T. (2003) Research Method for Business Student, third edition._Pretence Hall Financial Times.

[30] Shoniregun C.A, (2005) "Impacts and Risk Assessment of Technology for Internet Security: Enabled Information Small- Medium Enterprises', ISBN: 0-38724341-0

[31]Sivin-Kachala, J., \& Bialo, E. (2000). 2000 "research report on the effectiveness of technology in schools" (7th ed.). Washington, DC: Software and Information Industry Association.

[32]Strauss A. \& Corbin J., (1990) Basics of Qualitative Research. Newbury Park CA: SAGE, 1990.

[33]Turban E. and King D. (2003) "Introduction to ECommerce” Prentice Hall. Pearson Education, Upper Saddle River, New Jersey. United States. ISBN: 0-13122450-6

[34] Turban E., King D., Lee J., Liang T., and Turban D., (2010) A managerial Perspective, E-Commerce. $6^{\text {th }}$ Edition.

[35] UNCTAD (2003) “Africa’s Technology Gap, Case Studies on Kenya, Ghana, Uganda and Tanzania”. United Nations Publication. http://www.unctad.info/ upload/STDEV/docs/gap.pdf

[36] Webometric Ranking (2010) Ghana Web. http://www.ghanaweb.com/GhanaHomePage/education/un iversities.html. (Access date: $11^{\text {th }}$ October 2010).

[37] Westphal, L.E., Kim, L., Dahlman, C.J., (1985) Reflections on the Republic of Korea's acquisition of technological capability. In: Rosenberg, N., Frischtak, C. (Eds.), International Technology Transfer: Concepts, Measures and Comparisons. Praeger, New York, p. 167221.

[38] Worldbank (2009) "Ghana at a Glance" available at http://devdata.worldbank.org/AAG/gha_aag.pdf; viewed on the $1^{\text {st }}$ of October 2010. 